\title{
Correspondence
}

\section{Synovial amyloid deposits and chronic haemodialysis}

SIR, In their recent paper Muñoz-Gómez et al ${ }^{1}$ suggested that localised synovial amyloidosis might be peculiar to chronic renal failure treated with periodical haemodialysis, and they made the assumption that it was the cause of an arthropathy. In fact localised amyloid deposition in synovium and also in articular cartilage is a common aging phenomenon ${ }^{2}$ apparently associated with osteoarthrosis, and it is relevant that four of the seven patients studied were aged 50 years or more. This type of aging deposit was actually referred to in the preceding editorial as 'joint capsule and articular cartilage' deposition. ${ }^{3}$ The nature and extent of synovial amyloid deposits described in the article did not appear to differ from those associated with aging, and I would suggest that the finding of such deposits may represent no more than an accelerated age change. It is of interest in this context that synovial and articular cartilage amyloid deposits in patients with the so called amyloid arthropathy syndrome of multiple myeloma and primary amyloidosis do not appear to differ qualitatively from aging deposits either. ${ }^{4}$ Such patients may, however, show gross soft tissue amyloid deposition around joints.

The finding of synovial amyloid deposits in chronic haemodialysis patients may be unrelated to any arthropathy present and should not prevent other causes for an arthropathy from being sought.

Dept of Histopathology,

NATHANIEL. CARY

Charing Cross Hospital,

Fulham Palace Road,

London W6 8RF.

\section{References}

1 Muñoz-Gómez J. Bergadá-Barado E. Gómez-Pćrez R, et al. Amyloid arthropathy in patients undergoing periodical hacmodialysis for chronic renal failure: a new complication. Ann Rheum Dis 1985: 44: 729-33

2 Mitrovic D R, Stankovic A, Quintero M. Ryckewaert A. Amyloid deposits in human knec and hip joints. Rheumatol Int 1985: 5: 83-9.

3 Rowe I F. Editorial: Amyloid arthropathy. Ann Rheum Dis 1985: 44: $727-8$

4 Cary N R B. Clinicopathological importance of deposits of amyloid in the femoral head. J Clin Pathol 1985; 38: 868-72.

SIR, Recently, the biochemical nature of amyloid fibrils in haemodialysis associated amyloidosis has been characterised.' Amyloid fibrils isolated from tissue containing amyloid obtained during carpal tunnel decompression from a patient undergoing long term haemodialysis were found to contain as a major component a protein homologous to the normal plasma protein $\beta_{2}$-micro- $\frac{\bar{\omega}}{\bar{D}}$ globulin. This protein has not previously been shown to be $\mathbb{Q}$ a fibril constituent in amyloid deposits. $\beta_{2}$-Microglobulin is known to accumulate in the circulation of patients undergoing haemodialysis since this procedure does not remove $\overrightarrow{0}$ the protein from the plasma, ${ }^{2} 3$ and Gejyo et al postulate that sustained increase of plasma concentrations of $\vec{\omega}$ $\beta_{2}$-microglobulin leads to the accumulation of protein in tissues, causing the formation of amyloid fibrils. ' Interestingly, both $\mathrm{AL}$ amyloid fibrils ${ }^{4}$ and $\beta_{2}$-microglobulin derived fibrils appear to have a relatively high or affinity for the carpal tunnel, and in both cases precursor proteins are related to immunoglobulins.

It is likely that the amyloid deposits in the joints of $\frac{\infty}{\sigma}$ patients undergoing long term haemodialysis also contain o $\beta_{2}$-microglobulin as the fibril precursor, and it may be possible to confirm this relatively easily by immunohistochemical techniques. Similarly, although the biochemical nature of amyloid deposits in osteoarthritic joints has not been characterised, it should be possible to determine $\vec{c}$ whether these or any other age related amyloid deposits contain $\beta_{2}$-microglobulin.

Department of Rheumatology,

St Stephen's Hospital,

London SW10 9TH

\section{References}

1 Gejyo $\mathrm{F}$. Yamada $\mathrm{T}$. Odani $\mathrm{S}$ et al A new form of amyloid protein associated with chronic hemodialysis was identified as? $\beta_{2}$-microglobulin. Biochem Biophys Res Commun 1985; 129: 701-6.

2 Vincent C, Revillard J P. Galland M. Traegar J. Scrum $\beta_{2}$ ? microglobulin in hemodialysed patients. Nephron 1978: 21: 260-8.

3 Wibell L, Evrin P E, Berggard I. Serum $\beta_{2}$-microglobulin in 응 renal diseases. Nephron 1973; 10: 320-31.

4 Cohen A S. Canoso J J. Rheumatological aspects of amyloid discase. Clin Rheum Dis 1975: 1: 149-61.

\section{Combination chemotherapy in rheumatoid arthritis}

SIR, Would that the situation as outlined by Dr Bamji were so simple. ${ }^{1}$

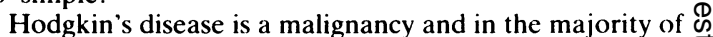
patients suffering from it the outcome, untreated, is death. Justification for using such toxic regimens is therefore easy and indeed giant strides have been made in improving $\underset{\Phi}{\Phi}$ survival. Rheumatoid arthritis cannot be considered com- $\stackrel{\mathcal{T}}{\Psi}$ parable. Whether we are right in considering it to be a non- $\varrho$ malignant B lymphoproliferative disease remains to be $\sigma$ 
seen, but for the majority of patients the slight reduction in longevity is in no way equivalent to that in the lymphomas. While we may anguish over the ravaging and debilitating aspects of this disease, I do not think this justifies, at the present time, trials with these drugs which have known severe short and long term side effects, especially when we have not even illustrated that we can carry out adequate trials of our current second line agents nor agree on acceptable measures of disease outcome.

One further point is pertinent. If sums of money similar to those poured into cancer research had been made available for research into rheumatic diseases, always unfashionable with both public and media, then I am sure we would be in a better position to answer many of the above questions.

Department of Rheumatology,

G R STRUTHERS

Selly Oak Hospital,

Birmingham B29 6JD.

\section{Reference}

1 Bamji A. Combination therapy in rheumatoid arthritis. Ann Rheum Dis 1985; 44: 862.

\section{Sulphasalazine therapy in RA}

SIR, Pullar et al reported recently the effect of acetylator phenotype on the efficacy of sulphasalazine therapy in rheumatoid arthritis (RA). ' We would largely agree with their conclusion that there is little practical value in determining acetylator phenotype before therapy ${ }^{2}$ but would like to comment on the incidence of slow and fast acetylator phenotypes in RA and the suggestion that fast acetylators may be subject to more severe disease.

During the course of investigations on the use of sulphasalazine in RA we have phenotyped 108 patients using a modification of Schroder's method. ${ }^{3}$ Thirty three patients $(30 \cdot 6 \%)$ were male and $80(74 \cdot 1 \%)$ were seropositive. Sixty two $(57 \cdot 4 \%)$ of our patients were slow acetylators, a figure which is in agreement with the reported incidence in the general UK population ${ }^{4}$ and other studies of RA patients. 56

It is always dangerous to decide what is serious or mild disease at a single point in the evolution of a chronic relapsing disorder, but all of our patients were felt to have disease of sufficient severity to warrant second line therapy, and the mean erythrocyte sedimentation rates $(\mathrm{mm} / 1 \mathrm{st} \mathrm{h})$ at the start of treatment with sulphasalazine were 50.2 (SD 29.4) in the slow acetylators and 51.7 (SD $24 \cdot 5$ ) in the fast. There is no statistical difference between these figures.

We would conclude therefore that the distribution of acetylator phenotype in patients with RA is the same as that in the general population and that acetylator phenotype has no bearing on the severity of RA.

Rheumatism Research Unit,

R S AMOS

Nether Edge Hospital,

D E BAX

Sheffield S11 9EL

\section{References}

1 Pullar T, Hunter J A, Capell H A. Effect of acetylator phenotype on efficacy and toxicity of sulphasalazine in rheumatoid arthritis. Ann Rheum Dis 1985: 44: 833-7.

2 Bax D E, Greaves M S, Amos R S. Sulphasalazine for rheumatoid arthritis: relationship between dose, acetylator phenotype and response to therapy. $\mathrm{Br} J$ Rheumatol (in press).

3 Schroder H. Simplified method for determining acetylator phenotype. $\mathrm{Br}$ Med J 1972; iii: 506-7.

4 Price Evans D A. An improved and simplified method of detecting the acetylator phenotype. J Med Genet 1969; 6: 405-7.

5 Lawson D H, Henry D A, Lowe J. Reavey P. Rennic J A N, Solomon A. Acetylator phenotype in spontaneous SLE and rheumatoid arthritis. Ann Rheum Dis 1979; 38: 171-3.

6 Ehrenfeld M, Zylber Katz E, Levy M. Acetylator phenotype in rheumatoid arthritis. Isr J Med Sci 1983; 19: 368-70.

\section{Retroviruses in rheumatoid arthritis}

SIR, Rheumatoid arthritis (RA) is characterised by both in vivo and in vitro depression of cell mediated immunity. The mechanism for this depressed cellular immunity is not known but may be due to deficient interleukin-2 production. ' Since retroviruses have been associated with deficiencies of immune reactivity we used standard techniques to look for the presence of antibodies to the human $\mathrm{T}$ cell retroviruses (HTLV-I, II, and III) in the sera from 60 patients with classical or definite rheumatoid arthritis. ${ }^{2.3}$ The results were uniformly negative. Since RA is linked to HLA-DR4 these findings indicate that false positivity on this account might be a rare event. ${ }^{4}$ It may be concluded from this work that if retroviruses are involved in the pathogenesis of rheumatoid arthritis then they are not serologically related to the known retroviruses as detected by presently available techniques.

Rheumatology Unit,

G S PANAYI

Dept of Medicine,

Guy’s Hospital Medical School,

London SE1 9RT.

The Institute of Cancer Research,

A G DALGLEISH

Chester Beatty Laboratories,

Fulham Road,

London, SW3 6JB.

\section{References}

1 Emery P. Panayi G S. Nouri A M E. Interleukin-2 reverses deficient cell-mediated immune responses in rhcumatoid arthritis. Clin Exp Immunol 1984: 57: 123-9.

2 Tedder R S. Shanson D C, Jeffries D J. et al. Low prevalence in the UK of HTLV-I and HTLV-II infection in subjects with AIDS, with extended lymphadenopathy and at risk of AIDS. Lancet 1984: ii: 125-8.

3 Cheingsong-Popov R. Weiss R A. Dalgleish A. et al. Prevalence of antibody to human T-lymphotropic virus type III in AIDS and AIDS-risk patients in Britain. Lancet 1984; ii; 477-9.

4 Weiss S H, Mann D L. Murray C. Popovic M. HLA-DR antsbodies and HTLV-III antibody ELISA testing. Lancet 1985; ii: 157 . 